\title{
A Fuzzy-Based Decision Support Model for Selecting the Best Dialyser Flux in Haemodialysis
}

\author{
Necla Öztürk ${ }^{1^{*}}$ and Hakan Tozan ${ }^{2}$ \\ ${ }^{I}$ Marmara University, Institute for Graduate Studies in Pure and Applied Science, \\ Department of Engineering Management, Kadıköy-Istanbul, Turkey \\ ${ }^{2}$ Turkish Naval Academy, Department of Industrial Engineering, \\ Tuzla-Istanbul, Turkey
}

Submitted April 2015. Accepted for publication May 2015.

\begin{abstract}
Decision making is an important procedure for every organization. The procedure is particularly challenging for complicated multi-criteria problems. Selection of dialyser flux is one of the decisions routinely made for haemodialysis treatment provided for chronic kidney failure patients. This study provides a decision support model for selecting the best dialyser flux between high-flux and low-flux dialyser alternatives. The preferences of decision makers were collected via a questionnaire. A total of 45 questionnaires filled by dialysis physicians and nephrologists were assessed. A hybrid fuzzy-based decision support software that enables the use of Analytic Hierarchy Process (AHP), Fuzzy Analytic Hierarchy Process (FAHP), Analytic Network Process (ANP), and Fuzzy Analytic Network Process (FANP) was used to evaluate the flux selection model. In conclusion, the results showed that a high-flux dialyser is the best option for haemodialysis treatment.
\end{abstract}

Keywords: decision making, FAHP, FANP, dialyser flux selection

\section{INTRODUCTION}

Decision making is currently one of the most critical management issues because several criteria and alternatives often exist for every decision. It is crucial to make the proper decisions in both the short and long terms because they define the survival, success, or growth of an organisation. In general, the decision-making process should consider not only concrete criteria, such as technical and economic properties, but also social, environmental, and political factors [1].

In addition to data collection, an efficient and cost-effective decision-making process should apply decision-making techniques. In the current highly competitive environment, the application of decision-making systems or methodologies gives an organization a competitive advantage. In most decision-making cases, there is more

*Corresponding author: Necla Öztürk, Institute for Graduate Studies in Pure and Applied Science, Department of Engineering Management, 34722, Kadıköy-Istanbul, Turkey. Phone: (0090) 5322780582. E-mail: neclaozturk@marun.edu.tr. Other author:htozan@dho.edu.tr. 
than one criterion to evaluate, and such decision-making processes are called MultiCriteria Decision Making (MCDM) [2].

Due to the widespread use of high technology, the recent decisions made in the healthcare sector are accompanied with many alternatives available. The physicians or healthcare professionals involved in the decision-making process of selecting any medical device, disposable product, or treatment alternative must evaluate the status of the patient, various criteria, and the alternatives available. Particularly in cases of chronic illnesses, routine decisions need to be made frequently.

In end-stage renal disease (ESRD), the progression of renal failure is characterized by the deterioration of various biochemical and physiological functions [3]. Only a small portion of ESRD patients are treated with a renal replacement therapy or renal transplantation [4,5]. The vast majority of ESRD patients are treated with haemodialysis with an extracorporeal circuit that consists of disposable products, such as fistula needles, bloodlines, dialysers, and haemodialysis concentrates. Dialysis treatments are performed at public, private, and non-profit centres, in hospitals and limited-care facilities, and at patients' homes [4].

The dialyser is the most important component in haemodialysis machine because it removes uremic toxins. Dialysers are also called artificial kidneys and can be classified according to their characteristics, such as membrane type and geometric structure. The flux of a dialyser is also one of these classification criteria [6]. Dialysers are classified as low-flux or high-flux [6], and the dialyser flux is selected by nephrologists or dialysis physicians. The dialyser flux selection process is a complicated process due to a large number of haemodialysis patients, the treatment frequency, the cost of each treatment, and the available dialyser alternatives.

The aim of this study is to systematize the dialyser flux selection process through the use of MCDM techniques, such as Analytic Hierarchy Process (AHP), Fuzzy Analytic Hierarchy Process (FAHP), Analytic Network Process (ANP), and Fuzzy Analytic Network Process (FANP). The MCDM techniques used in this study, the decision support software (DSS), and the proposed dialyser flux selection method are described in the methodology section, followed by the results of the application, discussion, and the conclusion.

\section{METHODS}

\subsection{Analytic Hierarchy Process (AHP)}

The Analytic Hierarchy Process (AHP), first proposed by Thomas L. Saaty in the 1970s, is one of the MCDM techniques that consider the relative importance of alternatives. In summary, the AHP considers both objective and subjective criteria and involves pairwise comparisons. Its flexibility in terms of its potential use for the analysis of complex problems and its user friendliness have made the AHP one of the most popular MCDMs [1, 7]. AHP has been used for selection, evaluation, resource allocation, and forecasting in fields such as manufacturing, engineering, social science, and politics [8]. In any AHP model, the goal is set at the top of the hierarchical structure and is followed by the main criteria. If applicable, sub-criteria are written under the corresponding main criterion. The alternatives of the AHP model are set at the bottom of the hierarchy. A schematic representation of the AHP structure is given in Figure 1. 


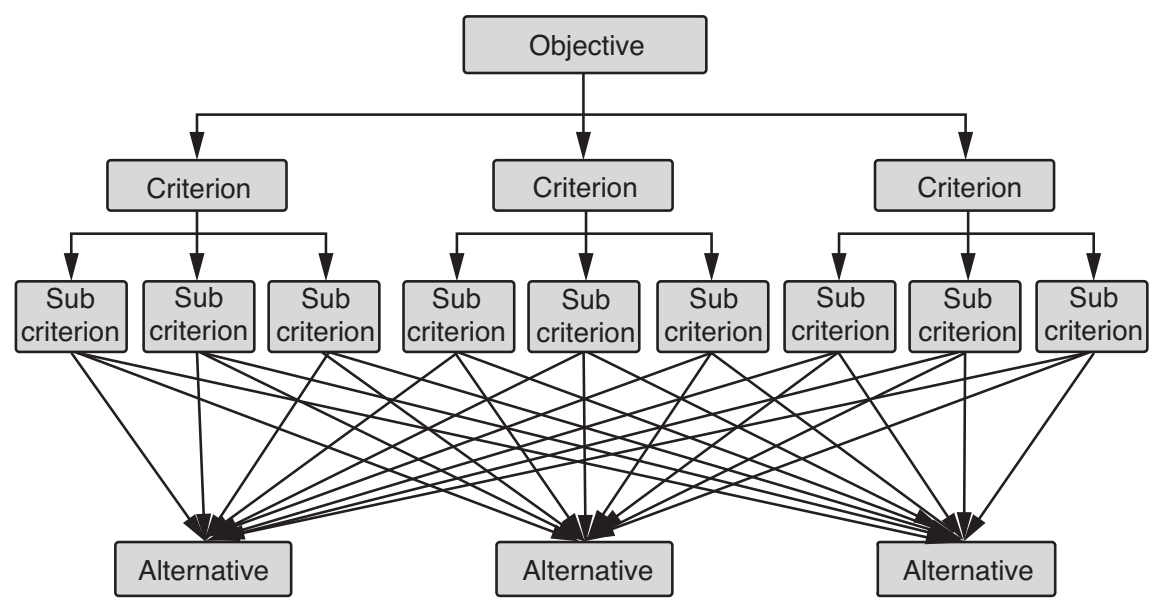

Figure 1. Schematic of AHP model.

The AHP methodology is based on the well-defined mathematical structure of consistent matrices and their associated right eigenvector's ability to generate true or approximate weights. In AHP, the criteria or alternatives are compared with respect to a criterion in a natural, pairwise mode. Individual preferences are converted to ratioscale weights, which can be combined into a linear additive weight $w(a)$ for each alternative $a$. The alternatives can then be compared and ranked.

The AHP model includes the following axioms: reciprocal, homogeneity, hierarchic composition, and involving expectations. The reciprocal axiom implies the following: if alternative $i$ is compared to alternative $j$, the comparison is defined as $a_{i j}$, and if alternative $j$ is compared to alternative $i$, the comparison is defined as $1 / a_{i j}$. The homogeneity axiom states that complexity should be structured in a hierarchy of homogenous clusters. The third axiom, namely hierarchic composition, stresses that judgments about or the priorities of the elements in a hierarchy do not depend on lowerlevel elements. The final axiom implies the involvement of the expectations [1].

The AHP methodology features the following steps:

1. Definition of the problem

2. Observation of the system

3. Construction of the hierarchical structure

4. Definition of the comparisons

5. Synthesis

6. Evaluation and results

The common scale shown in Table 1 is most often used to compare the criteria and alternatives.

\subsection{Analytic Network Process (ANP)}

Another MCDM technique is the Analytic Hierarchy Process (ANP) developed by Saaty in 1996. In ANP, the alternatives that affect the objective are grouped by their relationships to each other. ANP supports not only hierarchical problems but also 
Table 1. The Saaty rating Scale.

\begin{tabular}{lll}
\hline $\begin{array}{l}\text { Intensity of } \\
\text { importance }\end{array}$ & \multicolumn{1}{c}{ Definition } & \multicolumn{1}{c}{ Explanation } \\
\hline 1 & $\begin{array}{l}\text { Equal importance } \\
\text { Somewhat more } \\
\text { important } \\
\text { Much more important }\end{array}$ & $\begin{array}{l}\text { Two factors contribute to the objective. } \\
\text { Experience and judgement slightly favour one } \\
\text { over the other. } \\
\text { Experience and judgement strongly favour one over } \\
\text { the other. } \\
\text { Experience and judgement very strongly favour } \\
\text { one over the other. Its importance is } \\
\text { demonstrated in practice. } \\
\text { The evidence favouring one over the other is of } \\
\text { the highest possible validity. } \\
\text { When compromise is needed. }\end{array}$ \\
\hline $\begin{array}{l}\text { Very much more } \\
\text { important }\end{array}$ & $\begin{array}{l}\text { Absolutely more } \\
\text { important } \\
\text { Intermediate values }\end{array}$ &
\end{tabular}

problems modelled as a network. Because of the interaction and dependency of a higher-order criterion on a lower-level sub-criterion, it is not always possible to model every problem hierarchically.

In comparison to the AHP, the ANP has a more general structure. In ANP, there is a feedback mechanism which allows the dependency both among criteria and alternatives and among alternatives. More complex decisions can be modelled appropriately with ANP [1].

The ANP structure is composed of clusters and the influences between the clusters. One of the clusters contains the alternatives. The influences can be either inner dependency or feedback from another cluster. The inner dependency is shown with a curved arrow pointing to the same cluster. The straight arrows represent the dependencies between the clusters, and the cluster that the arrow points to influences the root cluster of the arrow. Figure 2 shows the schematic representation of the ANP structure. First, pairwise matrices for each criterion with the affected criteria of all the clusters have to be constructed. To be able to define the priorities in feedback mechanism models, a super-matrix method is developed. With a super-matrix, it is possible to consider all of the interactions between the effected criteria and the affecting criterion. A super-matrix is composed of pairwise comparisons of all of the possible pairs' priorities. In any super-matrix, the clusters are represented by $C_{N}, N=1,2 \ldots$, n, the elements of clusters are shown with $\mathrm{e}_{\mathrm{Nn}}$, and the priority vectors are denoted with Wij. A common scale shown in Table 1 can be used for the comparisons.

The ANP methodology features the following steps:

1. Definition of the problem

2. Construction of the relevant ANP model

3. Definition of the pairwise comparison matrices and priority vectors

4. Construction of the super-matrix

5. Evaluation and results 


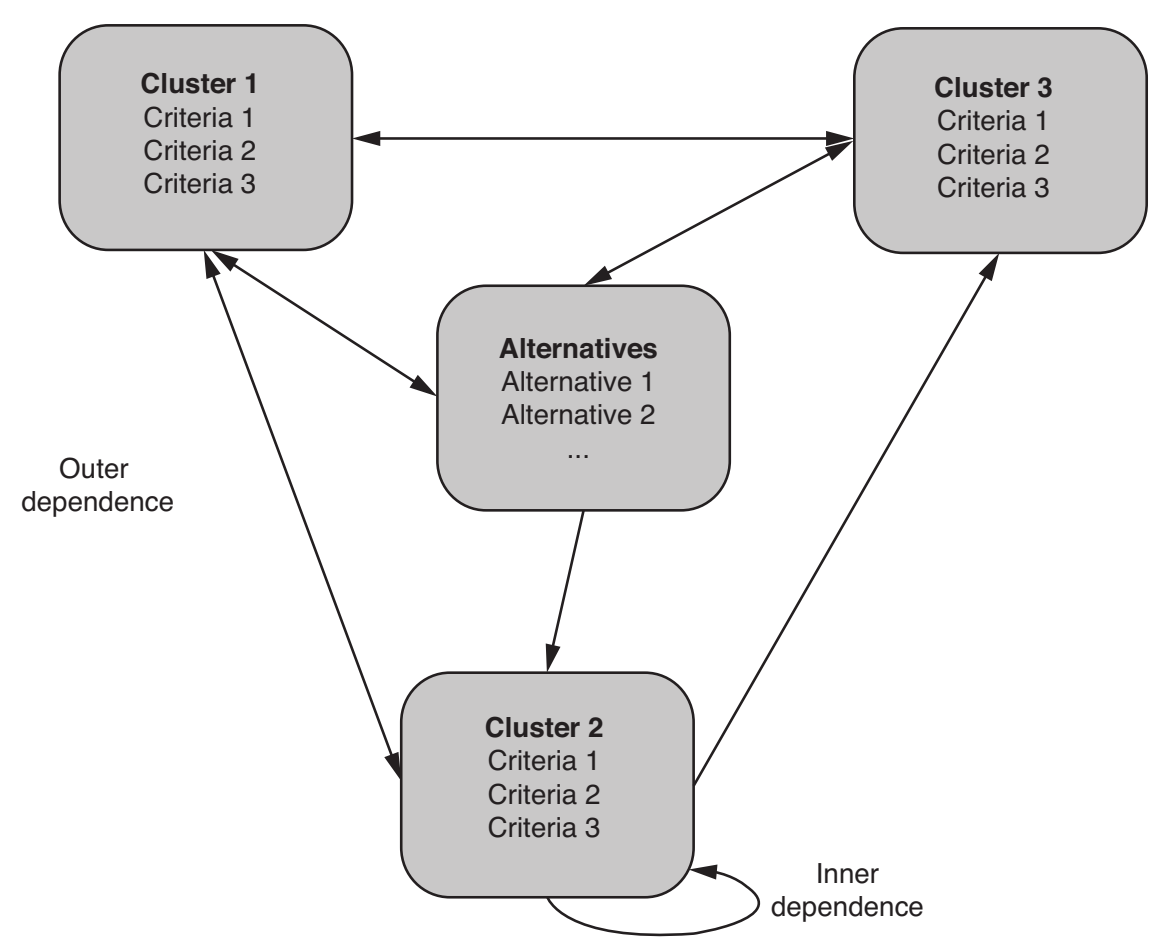

Figure 2. Schematic of ANP model.

\subsection{Fuzzy Analytic Hierarchy Process (FAHP) and Fuzzy Analytic Network Process (FANP)}

Fuzzy set theory was first introduced by L.A. Zadeh in 1965 to deal with the vagueness of human thought. It was oriented toward the rationality of uncertainty due to imprecision or vagueness. The most important contribution of fuzzy set theory is its capability to represent vague data. Furthermore, the theory allows the definition of mathematical operators and programming that can be applied to the fuzzy domain [9].

In fuzzy sets, instead of crisp values such as 0 and 1, the interval between these values is basically used to define the membership. The fuzzy sets are defined by Zadeh as a class of objects with a continuum of membership grades. The value is determined based on a membership function. In general, a triangular membership function as presented in Figure 3 is used. In this function, $x_{1}$ is the smallest possible value, $x_{2}$ is the most promising value, and $\mathrm{x}_{3}$ is the largest possible value [1,2,9].

The fuzzy AHP and the fuzzy ANP can be solved by various fuzzy approaches. In this study, Chang's Extent Analysis is employed because of its simplicity and common usage $[2,10]$. 


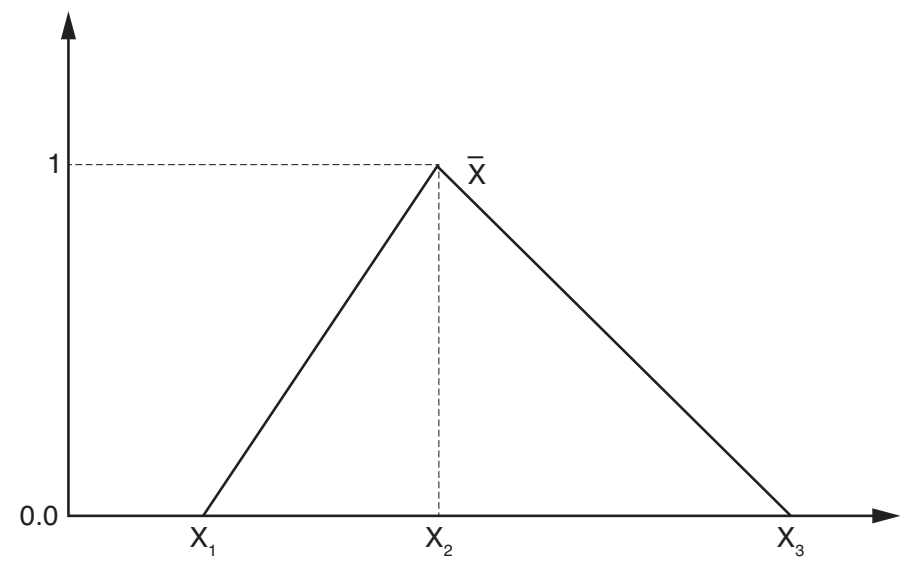

Figure 3. Triangular membership function [2].

A priority vector is calculated from a pairwise matrix by Chang's Extent Analysis method as follows:

Let $X=\left\{x_{1}, x_{2}, x_{3}, \ldots \ldots \ldots . ., x_{n}\right\}$ be an object set, and $G=\left\{g_{1}, g_{2}, g_{3}, \ldots \ldots \ldots ., g_{n}\right\}$ be a goal set. For each goal $i$, extent analysis is performed for each object $j$. Extent analysis values, $M_{g i}^{1}, M_{g i}^{2}, \ldots \ldots \ldots \ldots, M_{g i}^{m}, i=1,2, \ldots ., n$ (where $M_{g i}^{j}(\mathrm{j}=1,2, \ldots, \mathrm{m})$, are obtained.

Step 1: For each object $i$, the fuzzy synthetic extent value is obtained using the following equation:

$$
S_{i}=\sum_{j=1}^{m} M_{g i}^{j} \otimes\left[\sum_{i=1}^{n} \sum_{j=1}^{m} M_{g i}^{j}\right]^{-1}
$$

The value of $\sum_{j=1}^{m} M_{g i}^{j}$ is obtained by the following operation:

$$
\sum_{j=1}^{m} \boldsymbol{M}_{g i}^{j}=\left(\sum_{j=1}^{m} l_{j}, \sum_{j=1}^{m} m_{j}, \sum_{j=1}^{m} u_{j}\right) .
$$

The value of $\left[\sum_{i=1}^{n} \sum_{j=1}^{m} M_{g i}^{1}\right]^{-1}$ is obtained using the following operation:

$$
\left[\sum_{i=1}^{n} \sum_{j=1}^{m} M_{g i}^{j}\right]^{-1}=\left(\frac{1}{\sum_{i=1}^{n} u_{i}}, \frac{1}{\sum_{i=1}^{n} m_{i}}, \frac{1}{\sum_{i=1}^{n} l_{i}}\right) .
$$

Step 2: The degree of possibility for two fuzzy numbers, $M_{1}=\left(l_{1}, m_{1}, u_{1}\right)$ and $M_{2}=\left(l_{2}, m_{2}, u_{2}\right)$, where $M_{2} \geq M_{1}$, is defined as

$$
V\left(\tilde{M}_{2} \geq \tilde{M}_{1}\right)=\sup _{y \geq x}\left[\min \left(\mu_{\tilde{M}_{1}}(x), \mu_{\tilde{M}_{2}}(y)\right)\right] .
$$




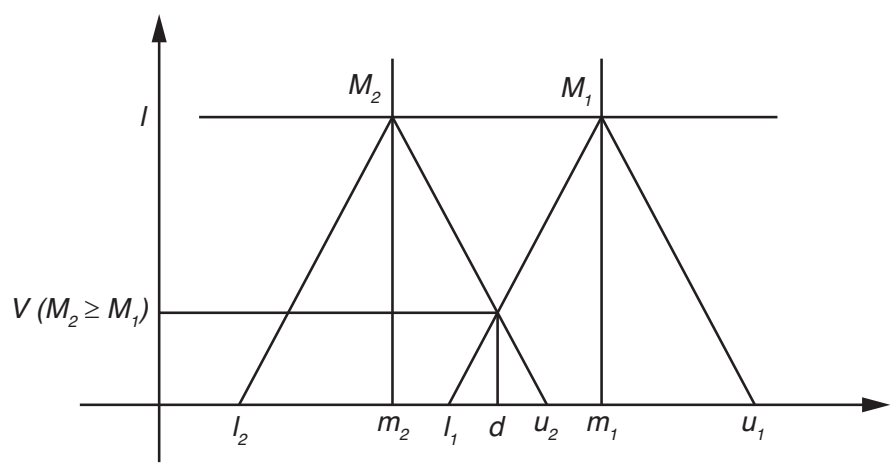

Figure 4. Triangular membership function showing an intersection between $M_{1}$ and $M_{2}[11]$.

Here, $\tilde{M}_{1}=\left(l_{1}, m_{1}, u_{1}\right)$ and $\tilde{M}_{2}=\left(l_{2}, m_{2}, u_{2}\right)$ are two triangular fuzzy numbers.

The last equation can be expressed as follows in Figure 4:

$$
\begin{aligned}
& V\left(\tilde{M}_{2} \geq \tilde{M}_{1}\right)=\operatorname{hgt}\left(\tilde{M}_{1} \cap \tilde{M}_{2}\right)=\mu_{M_{2}}(d) \\
& =\left\{\begin{array}{lll}
1, & \text { if } \quad & m_{2} \geq m_{1} \\
0, & \text { if } \quad l_{1} \geq u_{2} \\
& \frac{l_{1}-u_{2}}{\left(m_{2}-u_{2}\right)-\left(m_{1}-l_{1}\right)}, \text { otherwise }
\end{array}\right.
\end{aligned}
$$

Step 3: The degree of possibility for a convex fuzzy number $M$ to be greater than $k$ convex fuzzy numbers $M_{i}, i=1,2, \ldots, k$ can be defined by

$$
\begin{aligned}
& V\left(M \geq M_{1}, M_{2}, \ldots . M_{k}\right)=V\left[\left(M \geq M_{1}\right) \quad\right. \text { and } \\
& \left.\qquad\left(M \geq M_{2}\right) \quad \text { and....and } \quad\left(M \geq M_{k}\right)\right] \\
& =\min V\left(M \geq M_{i}\right) .
\end{aligned}
$$

Assuming that

$d^{\prime}\left(A_{i}\right)=\min V\left(S_{i} \geq S_{k}\right)$ for $k=1,2, \ldots, n ; k \neq i$,

the weight vector can be provided as

$$
W^{\prime}=\left(d^{\prime}\left(A_{1}\right), d^{\prime}\left(A_{2}\right), \ldots \ldots, d^{\prime}\left(A_{n}\right)\right)^{T},
$$

where $A_{i}=(i=1,2, \ldots, n)$.

Step 4: Finally, the normalized weight vectors can be computed as

$$
W=\left(d\left(A_{1}\right), d\left(A_{2}\right), \ldots \ldots, d\left(A_{n}\right)\right)^{T},,
$$

where $W$ is a non-fuzzy number $[2,10,11,12,13]$. 


\subsection{Decision Support Software (DSS)}

Organizations use DSSs for making decisions based on many criteria. Various DSSs have been developed since the early 1970s [14]. The DSS used in this study DSSw, was developed by Turkish Naval Academy (Istanbul, Turkey). It helps decision makers use AHP, FAHP, ANP, and FANP simultaneously and is able to analyse models with up to three levels of criteria, namely main criteria, sub-criteria, and sub-sub-criteria. DSSw was developed in the Microsoft Visual C\# programming language and retrieves data from Microsoft Excel. It is able to analyse any model and can include up to nine main criteria, nine sub-criteria for each main criteria and nine sub-sub-criteria for each sub-criteria [2].

The procedures to use DSSw are the following:

1. The criteria and alternatives are entered into a previously constructed Excel worksheet.

2. The software constructs a table to enter the influences between the criteria used for ANP and FANP.

3. The pairwise matrices produced by the Excel worksheet are filled by the user.

4. The consistency ratio of each matrix is calculated by the software, and in the case of a consistency ratio greater than 0.1 , the user is warned.

5. The software makes all of the calculations for AHP, FAHP, ANP, and FANP after all of the matrices are completed.

\subsection{Dialyser Flux Selection Model}

The choice of membrane polymer, the membrane form, and its physical and biological properties have changed continuously over time due to clinical demands [6]. Dialysers are classified based on their various characteristics. For instance, there are two types of dialyse constructions: parallel plate and hollow fiber. Recently, the most widely used dialysers are the hollow fiber dialysers. Dialysers can also be classified as cellulosebased and synthetic-based depending on the membrane employed. Another classification regards the permeability or flux of dialysers. Dialysers can be categorized into high-flux and low-flux dialysers. There are also middle-flux dialysers, but these are not widely used. The difference between high flux and low flux is the ultrafiltration coefficient $[6,15]$.

\subsubsection{Low-Flux Dialysers}

Cellulose-based membranes were the first commercial membranes for dialysis. They operate with a low flux. After the invention of synthetic-based membranes, some synthetic low-flux dialysers have been produced [6].

Low-flux dialysers are mostly used in standard haemodialysis treatments [16]. The mechanism for molecule removal in standard haemodialysis is diffusion, which enables the removal of substances with a molecular weight within a certain range. The sieving coefficients of low-flux dialysers are shown in Figure 5.

\subsubsection{High-Flux Dialysers}

Membranes of high hydraulic permeability (high-flux) started to be commercialized in 1971. Since 2000, the use of high-flux membranes has increased to $66 \%$ worldwide [17]. 




Figure 5. Sieving coefficients of low-flux and high-flux dialysers [3].

In contrast, the high-flux dialyser usage remains at $25.4 \%$ in the Turkish market [18]. The growth of high-flux dialyser usage in Turkey is apparently slower than the world average.

High-flux membranes are more permeable to substances of greater molecular weight. In contrast to low-flux dialysers, convection and diffusion are the mechanisms of molecule removal in high-flux dialysers [6]. High-flux dialysers can be used in high-flux dialysis, haemodiafiltration, and haemofiltration. The sieving coefficients of high-flux and low-flux dialysers are compared in Figure 5.

\subsubsection{The Model}

Selection of the flux type in haemodialysis treatment is one of the decisions that are routinely made by the dialysis personnel. In this study, a decision support model was constructed to select the best dialyser flux for haemodialysis.

The criteria were selected based on an in-depth review of the literature and comments from key decision makers [4, 19, 20, 21, 22, 23, 24, 25, 26]. Based on this analysis, the model was constructed with the following eight main criteria: cost, membrane material, medical assessment, technical infrastructure, knowledge, clearance, ultrafiltration coefficient, and toxin removal mechanism. The main criterion used for the medical assessment consists of three sub-criteria, including the removal of high-molecular-weight substances, anaemia correction, and survival. The model includes two flux alternatives, namely low flux and high flux. The hierarchical structure for AHP and FAHP is illustrated in Figure 6. The network structure of the model for ANP and FANP is presented in Figure 7. 


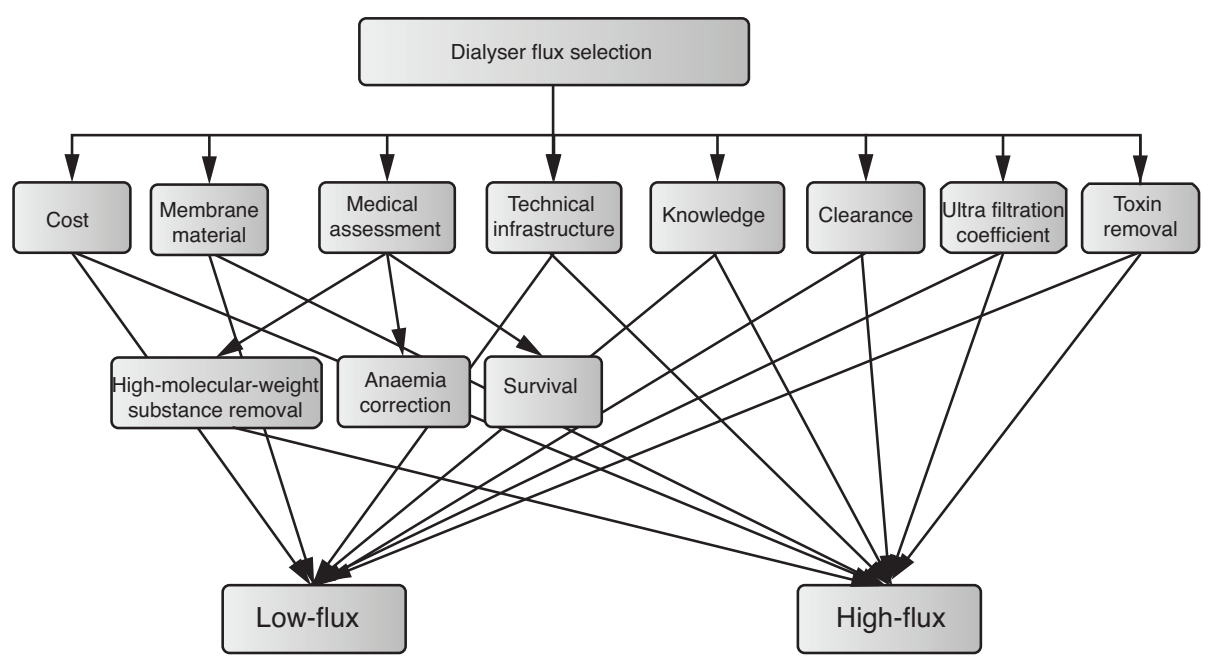

Figure 6. Hierarchical structure of the model for AHP and FAHP.

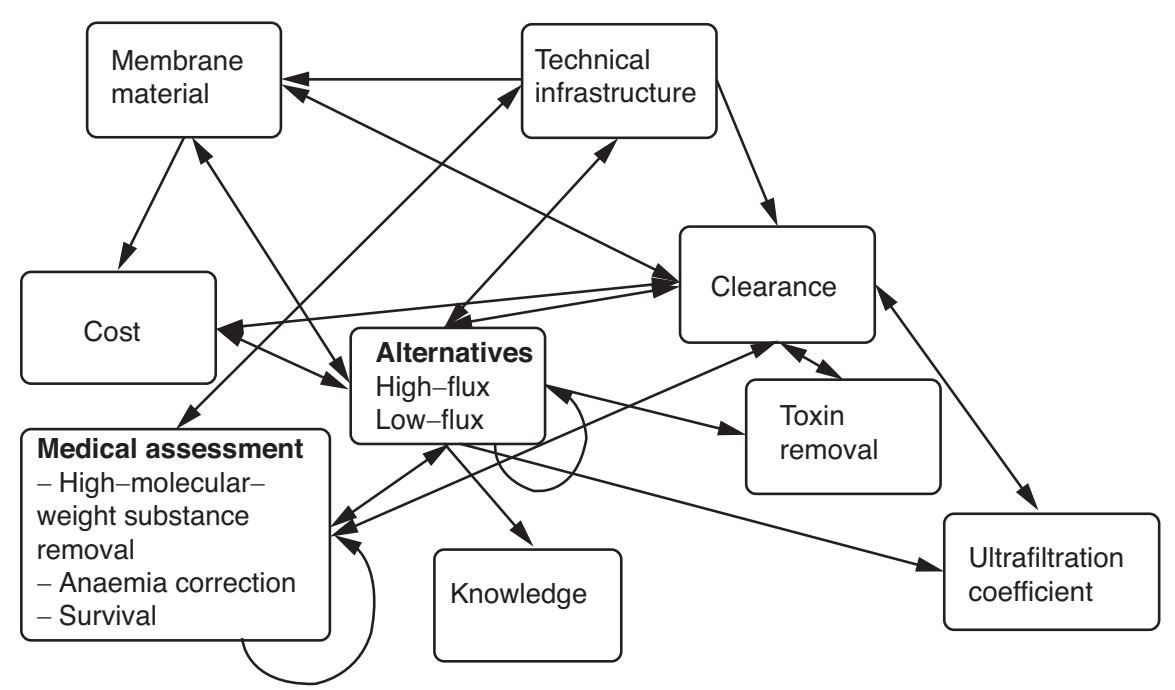

Figure 7. Network structure of the model for ANP and FANP.

The criteria for selecting the best dialyser flux are further described as follows:

Cost: Reimbursement for chronic dialysis accounts for a substantial portion of healthcare costs [27]. In price-sensitive markets such as Turkey, cost could be an independent decision criterion, even though cost is very closely linked to quality or properties of a dialyser. 
Membrane material: There are two distinctive classes of membrane materials, synthetic and cellulosic. Recently, $91 \%$ of the dialysers used worldwide were synthetic [6]. There are many types of synthetic membrane materials, and membrane material is one of the determinants of the degrees of dialyser biocompatibility and performance [6]. Moreover, the quality of the dialysis treatment is significantly affected by the polymer material chosen for dialysis membranes [5]. Some examples of synthetic membranes are polysulfone, polyacrylonitrile, and polyethersulfone [6].

Medical assessment: The adequacy of a haemodialysis treatment is influenced by many factors, but the long-term well-being of a patient is the priority. A dialysis physician's decision should be based on an overall assessment. In this study, under medical assessment, the removal of high-molecular-weight substances, anaemia control, and survival are prioritized.

High-molecular-weight substance removal: Higher-molecular-weight substances, such as beta-2-microglobulin, can be removed by convection. Accumulation of beta-2microglobulin causes dialysis-related amyloidosis [6, 19]. For the removal of highmolecular-weight substances, high-flux dialysers, which enable convective therapies, are essential [19, 25].

Anaemia: Renal anaemia is a major cause of morbidity and mortality in ESRD patients, and also lowers quality of life and cardiovascular functions [28, 29, 30, 31, 32]. Erythropoietin (EPO) deficiency, chronic blood loss, haemolysis, malnutrition and inflammation or infections are some causes of anaemia. Although Ayli et al. showed that high-flux membranes improve control of anaemia while allowing a progressive reduction in the exogenous EPO dose by $25-45 \%$, one of the most recent prospective controlled studies by Schneider et al. reported that high-flux dialysis offered no superior effects on haemoglobin levels $[33,34]$.

Survival: Mortality in ESRD patients is very high compared with that in the general population $[26,35]$. The adequacy and biocompatibility of the dialyser have direct or indirect effects on mortality. In addition to the common risk factors of mortality, ESRD patients are subjected to uraemia-related risk factors, such as anaemia, inadequate dialysis, and chronic inflammation.

Technical infrastructure: It has been proven that a dialyser is not a safe barrier to bacterial degradation products that might exist in the dialysate [19]. There is a risk of back filtration from the dialysate to the blood side $[36,37,38]$. The pressure gradient between the blood and the dialysate side is the identifier of back filtration [39]. Back filtration happens in conventional high-flux dialysis conditions with membranes having an ultrafiltration coefficient greater than $30 \mathrm{ml} / \mathrm{h} \cdot \mathrm{mmHG} \cdot \mathrm{m}^{2}$ [39]. For that reason, the back filtration risk is higher in high-flux dialysers. As a result, additional precautions must be taken in the treatment of the water [38]. One of the solutions to cope with back filtration is using dry powder bags for the bicarbonate concentrate and dialysis fluid filters in producing dialysis fluid [25, 38].

Knowledge: Healthcare professionals have to be aware of the flux differences. It is crucial that the medical benefits are understood. High-flux and low-flux dialysers have been compared in many retrospective and prospective studies [33, 40, 41, 42].

Clearance: Removing uremic toxins from the blood side to the dialysate side is the most important function of a dialyser. "Clearance" is the special term used to define the 
amount that is removed over a unit of time. This value, determined by in vitro laboratory testing, is presented as a table in the product brochure or instructions for use [6].

Ultrafiltration coefficient (UF Coeff.): The water permeability of a dialyser is characterised by the membrane ultrafiltration coefficient [6]. In addition to the toxins, the excess fluid in the body should also be removed during dialysis treatment. This water permeability is defined as the volumetric flow rate of water per unit area of membrane for unit pressure gradient [6]. Dialysers with a UF Coeff. greater than $15 \mathrm{ml} / \mathrm{h} / \mathrm{mmHg}$ are classified as high-flux dialysers [38].

Toxin removal mechanism: The only toxin removal mechanism in low-flux dialysis is diffusion, while toxin is removed by both diffusion and convection in high-flux dialysis. Higher-molecular-weight substances, such as beta-2-microglobulin, can be removed by convection $[6,19,43]$.

The influences between criteria for ANP and FANP are shown in Table 2.

Dialyser selection, including flux selection, is usually performed by dialysis physicians or nephrologists. The inputs for this model were gathered via a questionnaire completed by dialysis physicians and nephrologists. Pairwise comparisons between the criteria and alternatives were made using this questionnaire, as shown in Appendix. A total of 75 questionnaires were distributed to dialysis physicians and nephrologists working in hospitals and dialysis clinics in Turkey, and 47 questionnaires were returned. Some of the questionnaires were filled during direct visits, and some were sent by mail. Two of the questionnaires were eliminated due to missing information. Thus, 45 questionnaires were assessed in this study. The inputs that are essential for the computational part of DSSw were gathered by the questionnaire.

\section{RESULTS}

Using the developed model and DSSw, the best dialyser flux was selected with AHP, FAHP, ANP, and FANP. The geometric averages of the questionnaire responses were calculated. The pairwise matrices were determined and entered into DSSw. Figure 8 shows a screenshot of the results in DSSw. The results of the model are summarized in Table 3, showing that high-flux dialyser is a better option than low-flux dialyser for haemodialysis treatment by all four methods.

\section{DISCUSSION}

Advantages that are claimed to be provided by high-flux dialysers have been discussed in several multicentre, retrospective and prospective studies [33, 40, 41, 42, 44]. The worldwide usage of high-flux membranes for dialysis patients has increased from $46 \%$ in the year 2000 to $66 \%$ in the year 2009 [45]. In Turkey, the usage rate of high-flux dialysers in 2011 was $25.4 \%$ [18], which is far below the world average. The reason may be solely the very low reimbursement rate, which is $\$ 69$ per haemodialysis treatment. This amount is very low compared to countries such as the USA, Germany, Belgium, Netherlands, UK, and France, as discussed by Vanholder et al. [27].

The selection of the flux of dialysers involves the consideration of many parameters; it is difficult to prioritize among them. The reason underlying the low usage of high- 
Table 2. The influence between criteria.

\begin{tabular}{|c|c|}
\hline Influenced criteria & Influencing criteria \\
\hline Cost & $\begin{array}{l}\text { Membrane material, high-molecular-weight substance removal, } \\
\text { anaemia, knowledge, clearance, UF coeff., toxin removal, high-flux, } \\
\text { low-flux }\end{array}$ \\
\hline Membrane material & $\begin{array}{l}\text { Cost, high-molecular-weight substance removal, anaemia, survival, } \\
\text { knowledge, clearance, UF coeff., toxin removal, high-flux, low-flux }\end{array}$ \\
\hline $\begin{array}{l}\text { High molecular } \\
\text { substance removal }\end{array}$ & $\begin{array}{l}\text { Cost, membrane material, anaemia, survival, knowledge, } \\
\text { clearance, high-flux, low-flux }\end{array}$ \\
\hline Anaemia & $\begin{array}{l}\text { Cost, membrane material, survival, knowledge, clearance, high-flux, } \\
\text { low-flux }\end{array}$ \\
\hline Survival & $\begin{array}{l}\text { Cost, membrane material, anaemia, knowledge, clearance, high-flux, } \\
\text { low-flux }\end{array}$ \\
\hline Technical & High-molecular-weight substance removal, anaemia, survival, \\
\hline infrastructure & knowledge, clearance, UF coeff., toxin removal, high-flux, low-flux \\
\hline Knowledge & $\begin{array}{l}\text { Cost, membrane material, high-molecular-weight substance removal, } \\
\text { anaemia, survival, technical infrastructure, clearance, UF coeff., toxin } \\
\text { removal, high-flux, low-flux }\end{array}$ \\
\hline Clearance & $\begin{array}{l}\text { Cost, membrane material, high-molecular-weight substance removal, } \\
\text { anaemia, survival, knowledge, UF coeff., toxin removal, high-flux, } \\
\text { low-flux }\end{array}$ \\
\hline UF coeff. & $\begin{array}{l}\text { Cost, membrane material, high-molecular-weight substance removal, } \\
\text { anaemia, survival, knowledge, clearance, toxin removal, high-flux, low- } \\
\text { flux }\end{array}$ \\
\hline Toxin removal & $\begin{array}{l}\text { High-molecular-weight substance removal, anaemia, survival, technical } \\
\text { infrastructure, knowledge, clearance, UF coeff., high-flux, low-flux }\end{array}$ \\
\hline High-flux & $\begin{array}{l}\text { Cost, membrane material, high-molecular-weight substance removal, } \\
\text { anaemia, survival, technical infrastructure, knowledge, clearance, UF } \\
\text { coeff., toxin removal }\end{array}$ \\
\hline Low-flux & $\begin{array}{l}\text { Cost, membrane material, high-molecular-weight substance removal, } \\
\text { anaemia, survival, technical infrastructure, knowledge, clearance, UF } \\
\text { coeff., toxin removal }\end{array}$ \\
\hline
\end{tabular}

flux dialyser in Turkey is the consideration of only the cost of the dialysers. However, flux-selection decisions change when factors such as high-molecular-weight substance removal, anaemia control, survival, toxin removal mechanism, and clearance are also considered.

MCDM techniques are used in a wide variety of fields for decision making, including medical device selection. No study has been conducted on MCDM usage in dialyser selection. Only one study (Ronco et al. [16]) has proposed a database for all of the dialysers available on the market, that enables users to compare and select dialysers based on product specifications. Using the model developed in this study, it is possible to include related criteria when making a decision on the type of dialyser. 


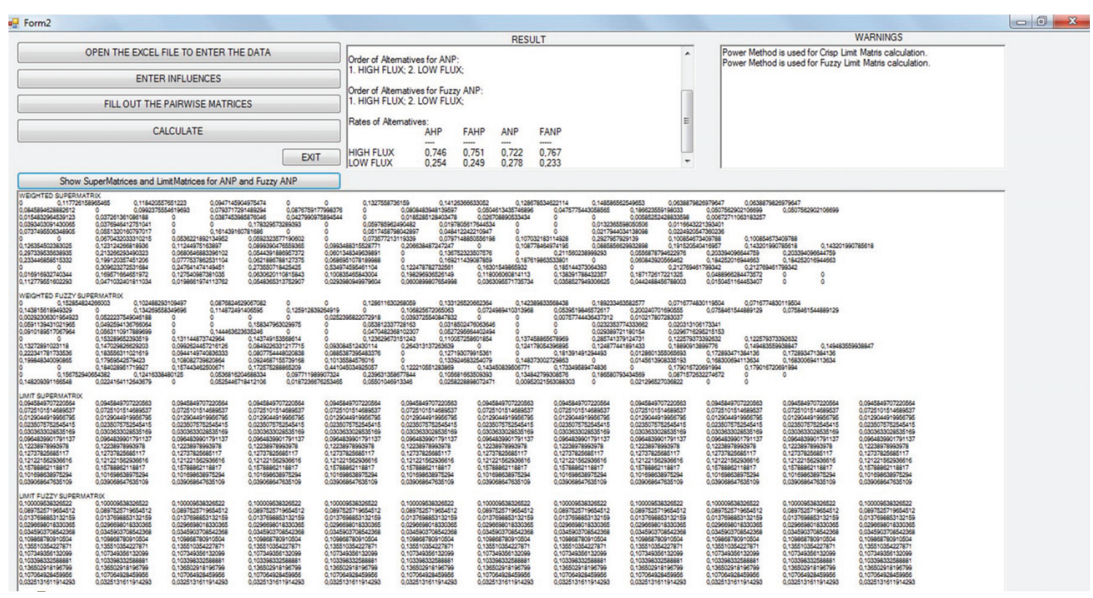

Figure 8. User interface of the DSSw showing the results of the decision support model for the selection of the best dialyser flux.

Table 3. Results of the dialyser flux selection model solved by DSSw.

\begin{tabular}{lcccc}
\hline Alternatives & AHP & FAHP & ANP & FANP \\
\hline High-flux dialyser & 0.746 & 0.751 & 0.722 & 0.767 \\
Low-flux dialyser & 0.254 & 0.249 & 0.278 & 0.233 \\
\hline
\end{tabular}

This study is the first in the literature to propose a decision support model for dialyser flux selection.

There are three main limitations of this study. First, the criteria might differ with a different group of key decision makers. Second, the current results are based on questionnaires completed by physicians in Turkey only, and may not be applicable to other parts of the world. Another limitation is that the current results are based on only 45 questionnaire responses received. The model can be applied to a future study involving a larger group of physicians in a wider geographical region.

\section{CONCLUSION}

In managing chronic diseases, the same decision has to be made routinely with only slight changes. Making the decision process systematic would save time and increase both the efficiency of the process and cost effectiveness. Selecting the best dialyser flux for dialysis, which is addressed in this study, is a good example of routing decisionmaking in chronic disease management. Efficient selection and effective usage of dialysers are of great importance to the physician in terms of the treatment quality and, to the patient, in terms of quality of life and survival. Governments around the world all 
attempt to control the rising costs of dialysis because they constitute an important part of healthcare expenses [27, 46, 47]. However, the priority of governments should be ensuring quality of care in addition to controlling the costs.

In this study, a model for selecting the best dialyser flux was constructed based on MCDM techniques, including AHP, FAHP, ANP, and FANP. High-flux dialysers were found to be the best alternative by all four techniques employed in this study. This study suggests that high-flux dialysers may be more widely accepted in coming years. Further research can be conducted by including more MCDM methods, such as ELECTRE, TOPSIS, and VIKOR, and involving a larger group of physicians in a wider geographical region.

\section{CONFLICT OF INTEREST}

The authors indicated no potential conflicts of interest.

\section{REFERENCES}

[1] Inan UH. Kalite yönetim sistemlerinde tetkik performansının bulanık mantık ile analitik hiyerarşi süreci ve bulanık analitik ăg süreci ve bulanık analitik ăg süreci kullanılarak ölçülmesi. PhD dissertation, Y1ldız Technical University, 2008.

[2] Yanar L, Tozan H. A fuzzy hybrid decision support system for interceptor baywatch boat propulsion system selection. Tehnički vjesnik, 2012, 19(2):407-413.

[3] Ronco C, Bowry S. Nanoscale modulation of the pore dimensions, size distribution, and structure of a new polysulfone-based high-flux dialysis membrane, The International Journal of Artificial Organs, 2001, 24(10):726-735.

[4] Locatelli F, Valderrabano F, Hoenich N, Bommer J, Leunissen K, Cambi V. Progress in dialysis technology: membrane selection and patient outcome. Nephrology Dialysis Transplant, 2000, 15(8):1133-1139.

[5] Ronco C, Nissenson AR. Does Nanotechnology Apply to Dialysis? Blood Purification, 2001, 19(4):347-352.

[6] Uhlenbush-Körwer I, Bonnie-Schorn E, Grassman A, Vienken J. Understanding membranes and dialysers, Pabst Science Publishers, Lengerich, 2004.

[7] Saaty TL, Wind Y. Marketing Applications of the Analytic Hierarchy Process. Management Science, 1980, 26(7):641-658.

[8] Vaidya OS, Kumar S. Analytic Hierarchy Process: An overview of Applications. European Journal of Operational Research, 2006, 169(1):1-29.

[9] Zadeh LA. Fuzzy Sets. Information and Control, 1965, 8:338-353.

[10] Cakir E, Tozan H, Vayvay O. A method for selecting third party logistic service provider using fuzzy AHP. Journal of Science and Engineering, 2009, 5(3):38-54.

[11] Kahraman C, Cebeci U, Ruan D. Multi-attribute Comparison of Catering Service Companies Using Fuzzy AHP: The Case of Turkey. International Journal of Production Economics, 2004, 87(2):171-184.

[12] Chang DY. Applications of the Extent Analysis Method on Fuzzy AHP. European Journal of Operations Research, 1996, 95(3):649-655.

[13] Chen SM. Evaluating Weapon Systems using Fuzzy Arithmetic Operations. Fuzzy Sets and Systems, 1996, 77(3):265-276.

[14] Sprague RH. A framework for the development of decision support systems. MIS Quarterly, 1980, 4(4):1-26.

[15] Schönweiss G. High-Flux-Dialyse in Dialyse Fibel, $2^{\text {nd }}$ ed., Abakiss Verlag, Bad Kissingen, 1996. 
[16] Ronco C, Ghezzi PM, Hoenich NA, Delfino P. Computerized Selection of Membranes and Hemodialyzers, in Ronco C, Winchester JF (ed). Dialysis, Dialyzers and Sorbents. Where are we going?, Karger Basel, 2001, 133:119-130.

[17] Fresenius Medical Care. ESRD patients in 2010: a global perspective, 2010. http:// vision-fmc.com/files/pdf/ERSD\%20Patients\%20in\%202010.pdf. Accessed September 15, 2014

[18] Turkish Society of Nephrology Registry. Registry of the nephrology, dialysis, and transplantation in Turkey, 2012. http://www.tsn.org.tr/folders/file/tsn_registry_2011.pdf. Accessed September 15, 2014

[19] Bowry SK, Gatti E, Vienken J. Contribution to polysulfone membranes to the success of convective dialysis therapies. Contributions to Nephrology, 2011, 173:110-118.

[20] Hakim RM, Wingard RL, Husni L, Parker RA, Parker TF. The effect of membrane biocompatibility on plasma beta-2-microglobulin parameters in chronic haemodialysis patients. Journal of American Society of Nephrology, 1996, 7(3):472-478.

[21] Hartmann J, Fricke H, Schiffl H. Biocompatible membranes preserve residual renal function in patients undergoing regular haemodialysis. American Journal of Kidney Disease, 1997, 30(3):366-373.

[22] Hornberger JC, Chernew M, Petersen J, Garber AM. A multivariate analysis of mortality and hospital admissions with high-flux dialysis. Journal of American Society of Nephrology, 1992, 3(6):1227-1237.

[23] Parker TF, Wingard RL, Husni L, Ikizler TA, Parker RA, Hakim RM. Effect of the membrane biocompatibility on nutritional parameters in chronic haemodialysis patients. Kidney International, 1996, 49(2):551-556.

[24] Skroeder NR, Jacobson SH, Lins LE, Kjellstrand CM. Biocompatibility of dialysis membranes is of no importance for objective or subjective symptoms during or after Haemodialysis. American Society for Artificial Internal Organs, 1990, 36(3):637-639.

[25] Asci G, Toz H, Ozkahya M, Duman S, Demirci MS, Cirit M, Sipahi S, Dheir H, Bozkurt D, Kırçelli F, Ok ES, Erten S, Ertilav M, Kose T, Başçı A, Raimann JG, Levin NW, Ok E. The impact of membrane permeability and dialysate purity on cardiovascular outcomes. Journal of American Society of Nephrology, 2013, 24(6):1014-1023.

[26] Ok E, Asci G, Toz H, Ok ES, Kircelli F, Yilmaz M, Hur E, Demirci MS, Demirci C, Duman S, Basci A, Adam SM, Isik IO, Zengin M, Suleymanlar G, Yilmaz ME. Mortality and cardiovascular events in online haemodiafiltration (OL-HDF) compared with high-flux dialysis: results from the Turkish OLHDF Study. Nephrology Dialysis Transplantation, 2013, 28(1):192-202.

[27] Vanholder R, Davenport A, Tannedouche T, Kooman J, Kribben A, Lameire N, Lonnemann G, Magner P, Mendelssohn D, Saggi SJ, Shaffer RN, Moe SM, Biesen WV, van der Sande F, Mehrotra R, on behalf of the Dialysis Advisory Group of the American Society of Nephrology. Reimbursement of dialysis: a comparison of seven countries. Journal of American Society Nephrology, 2012, 23(8):1291-1298.

[28] Ma JZ, Ebben J, Xia H, Collins AL. Hematocrit levels and associated mortality in hemodialysis patients. Journal of American Society of Nephrology, 1999, 10(3):610-619.

[29] Ofsthun N, LaBreque J, Lacson E, Keen M, Lazarus JM. The effects of higher hemoglobin levels on mortality and hospitalization in hemodialysis patients. Kidney International, 2003, 63(5):1908-1914.

[30] Xia H, Ebben J, Ma JZ, Collins AL. Hematocrit levels and hospitalization risks in hemodialysis patients. Journal of American Society of Nephrology, 1999, 10(6):1309-1316.

[31] Young EW. Dialysis dose, membrane type, and anemia control. American Journal of Kidney Disease, 1998, 6(4):157-160.

[32] Bowry SK, Gatti E. Impact of hemodialysis therapy on anemia of chronic kidney disease: the potential mechanisms. Blood Purification, 2011, 32(3):210-219. 
[33] Ayli D, Ayli M, Azak A, Yüksel C, Koşmaz GP, Atilgan G, Dede F, Abayli E, Çamlıbel M. The effect of high flux hemodialysis on renal anemia. Journal of Nephrology, 2004, 17(5):701-706.

[34] Schneider A, Drechsler C, Krane V, Krieter DH, Scharnagl H, Schneider MP, Wanner C. The Effect of High-Flux Hemodialysis on Hemoglobin Concentrations in Patients with CKD: Results of the MINOXIS Study. Clinical Journal of American Society of Nephrology, 2012, 7(1):52-59.

[35] De Jager D, Grootendorst DC, Jager KJ, van Dijk PC, Tomas LMJ, Ansell D, Collart F, Finne P, Heaf JG, De Meester J, Wetzels JFM, Rosendaal FR, Dekker FW. Cardiovascular and non-cardiovascular mortality among patients starting dialysis. Journal of American Medical Association, 2009, 302(16):1782-1789.

[36] Klinkmann H, Ebbighausen H, Uhlenbusch I, Vienken J. High-flux dialysis, dialysate quality and backtransport. Contributional Nephrology, 1993, 103:89-97.

[37] Urena P, Herbelin A, Zingraff J, Lair M, Man NK, Descamps-Latscha B, Drüeke T. Permeability of cellulosic and non-cellulosic membranes to endotoxin sub units and cytokine production during invitro hemodialysis. Nephrology Dialysis Transplantation, 1992, 7(1):16-28.

[38] Schiffl H. High-Flux Dialyzers, Backfiltration, and Dialysis Fluid Quality. Seminars in Dialysis, 2011, 24(1):1-4.

[39] Baurmeister U, Vienken J, Daum V. High-Flux Dialysis Membranes: Endotoxin Transfer by Back Filtration can be a Problem. Nephrology Dialysis Transplantation, 1989, 4 (Suppl.):89-93.

[40] Bonforte G, Grillo P, Zerbi S, Surian M. Improvement of anemia in hemodialysis patients treated by hemodiafiltration with high-volume On-Line-prepared substitution fluid. Blood Purification, 2002, 20(4):357-363.

[41] Locatelli F, Martin-Malo A, Hannedouche T, Loureiro A, Papadimitriou M, Wizemann V, Jacobson SH, Czekalski S, Ronco S, Vanholder R. Effect of membrane permeability on survival of hemodialysis patients. Journal of American Society of Nephrology, 2009, 20(3):645-654.

[42] Pedrini LA, Cristofaro VD, Comelli M, Casino FG, Prencipe M, Baroni A, Campolo G, Manzoni C, Coli L, Ruggiero P, Acquistapace I, Auriemma L. Long-term effects of high-efficiency on-line haemodiafiltration on uraemic toxicity. A multicentre prospective randomized study. Journal of Nephrology Dialysis Transplant, 2011, 26(8):2617-2624.

[43] Pickett TM, Cruickshank A, Greenwood RN, Taube D, Davenport A, Farrington K. Membrane flux not biocompatibility determines beta-2-microglobulin levels in hemodialysis patients. Blood Purification, 2001, 20(2):161-166.

[44] Tattersall J, Canaud B, Heimburger H, Pedrini L, Schneditz D, Van Biesen W. High-flux or low-flux dialysis: a position statement following publication of the Membrane Permeability Outcome study. Nephrology Dialysis Transplant, 2010, 25(4):1230-1232.

[45] Blankestijn PJ, Ledebo I, Canaud B. Hemodiafiltration: clinical evidence and remaining questions. Kidney International, 2010, 77(7):581-587.

[46] Ishida K, Hirose M, Fujiwara K, Tsuruta H, Ikeda N. Analysis of Medical Equipment Management in Relation to the Mandatory Medical Equipment Safety Manager (MESM) in Japan. Journal of Healthcare Engineering, 2014, 5(3):329-346.

[47] Snyder R, Huynh N, Cai B, Tavakoii A. Evaluation of medication administration process: Tools and techniques. Journal of Healthcare Engineering, 2011, 2(4):527-538. 


\section{APPENDIX. QUESTIONNAIRE}

\section{Best Dialyser Flux Selection}

Decision making is both a hard and important issue especially in case of having multiple criteria, which is called as multi-criteria decision making.

Today, there are two alternatives of dialysers to be used in haemodialysis treatment Low Flux and High Flux dialysers. The decision made between these two alternatives is a multi-criteria-decision-making case.

This questionnaire is designed to be used in choosing the best dialyser flux. Criteria used in this survey are defined with the support of experts. The criteria used are cost of dialyser, membrane material, medical assessment, high-molecular-weight substance removal, anaemia correction, survival, technical infrastructure, ultrafiltration coefficient, toxin removal, knowledge, and clearance.

You are asked to kindly compare these criteria for flux selection:

1. Between criteria.

2. Between alternatives.

For the comparisons, please use the "Saaty rating scale" given below along with an example of response:

What is the importance of "Cost of dialyser" in comparison to other criteria?

\begin{tabular}{|c|c|c|c|c|c|c|c|c|c|c|c|c|c|c|c|c|c|c|}
\hline Criterion & 9 & 8 & 7 & 6 & 5 & 4 & 3 & 2 & 1 & 2 & 3 & 4 & 5 & 6 & 7 & 8 & 9 & Criterion \\
\hline \multirow{7}{*}{ Cost } & & & & & & & & & & & $\mathrm{X}$ & & & & & & & Membrane \\
\hline & & & & & $X$ & & & & & & & & & & & & & Medical \\
\hline & & & & & & & & & & & & & & & & & $\mathrm{X}$ & Technical \\
\hline & & & & & $\mathrm{X}$ & & & & & & & & & & & & & Knowledge \\
\hline & & & & & & & & & & & & & $\mathrm{X}$ & & & & & Clearance \\
\hline & & & $X$ & & & & & & & & & & & & & & & KUF \\
\hline & & & & & & & & & $X$ & & & & & & & & & Toxin removal \\
\hline
\end{tabular}

Thanks a lot for your interest and time,

Sincerely,

Necla Öztürk

Note: Please do not mention your name. 
The Saaty Rating Scales:

\begin{tabular}{lll}
$\begin{array}{l}\text { Intensity of } \\
\text { importance }\end{array}$ & \multicolumn{1}{c}{ Definition } & \multicolumn{1}{c}{ Explanation } \\
\hline 1 & $\begin{array}{l}\text { Equal importance } \\
\text { Somewhat more important }\end{array}$ & $\begin{array}{l}\text { Two factors contribute to the objective. } \\
\text { Experience and judgement slightly favour one } \\
\text { over the other. } \\
\text { Experience and judgement strongly favour one } \\
\text { over the other. } \\
\text { Experience and judgement very strongly favour } \\
\text { one over the other. Its importance is demonstrated } \\
\text { in practice. } \\
\text { The evidence favouring one over the other is of } \\
\text { the highest possible validity. } \\
\text { When compromise is needed. }\end{array}$ \\
\hline & Very much more important \\
\hline $2,4,6,8$ & Intermediate values &
\end{tabular}

$\begin{array}{ll}\text { Abbreviations used in the following questionnaire are as follows: } \\ \text { Cost of dialyser } & \text { Cost } \\ \text { Membrane material } & \text { Membrane } \\ \text { Medical assessment } & \text { Medical } \\ \text { High-molecular-weight substance removal (ör. B2) } & \text { High molecule } \\ \text { Anaemia correction } & \text { Anaemia } \\ \text { Technical infrastructure } & \text { Technical } \\ \text { Ultrafiltration coefficient } & \text { KUF }\end{array}$

Please compare among criteria depending on objective:

I- What is the importance of "Cost of dialyser" in comparison to other criteria?

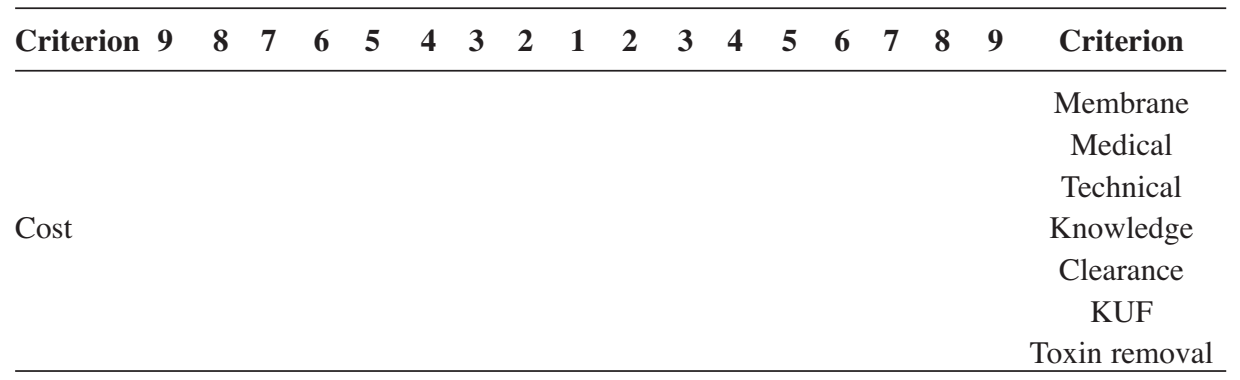

II- What is the importance of "Membrane material" in comparison to other criteria?

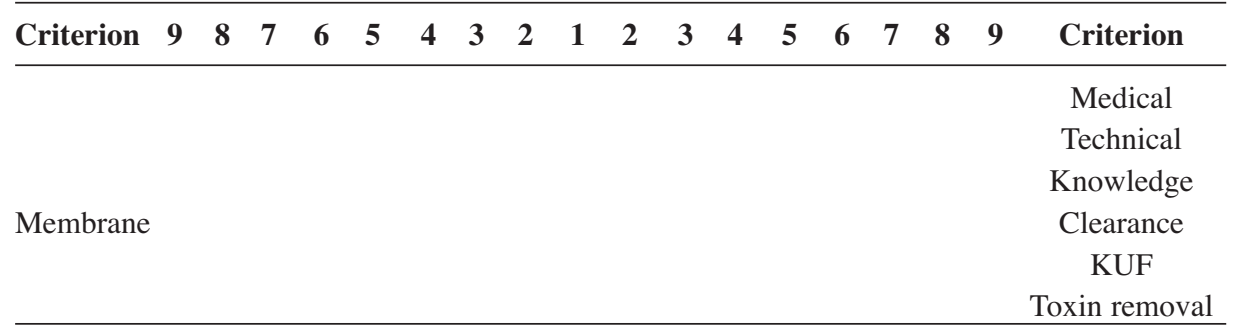


III- What is the importance of "Medical assessment" in comparison to other criteria?

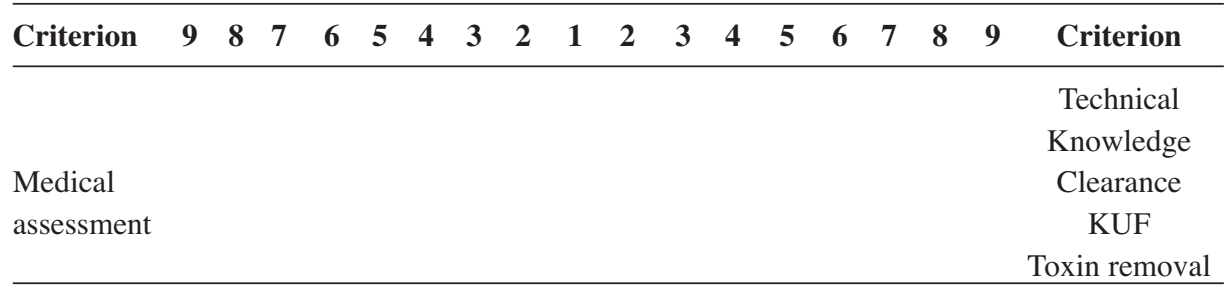

IV- What is the importance of "Technical infrastructure" in comparison to other criteria?

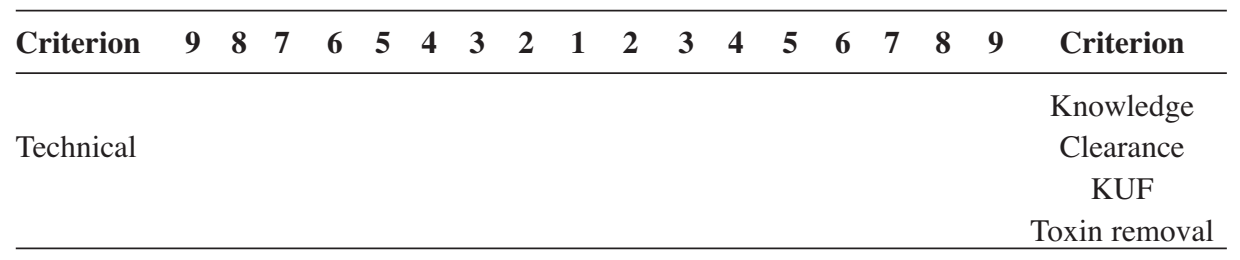

V- What is the importance of "Knowledge" in comparison to other criteria?

\begin{tabular}{llllllllllllllllllll}
\hline Criterion & 9 & $\mathbf{8}$ & $\mathbf{7}$ & $\mathbf{6}$ & $\mathbf{5}$ & $\mathbf{4}$ & $\mathbf{3}$ & $\mathbf{2}$ & $\mathbf{1}$ & $\mathbf{2}$ & $\mathbf{3}$ & $\mathbf{4}$ & $\mathbf{5}$ & $\mathbf{6}$ & $\mathbf{7}$ & $\mathbf{8}$ & $\mathbf{9}$ & Criterion \\
\hline & & & & & & & & & & & & & & & & & & & Clearance \\
Knowledge & & & & & & & & & & & & & & & & & & $\begin{array}{c}\text { KUF } \\
\text { Toxin removal }\end{array}$ \\
\hline
\end{tabular}

VI- What is the importance of "Clearance" in comparison to other criteria?

\begin{tabular}{|c|c|c|c|c|c|c|c|c|c|c|c|c|c|c|c|c|c|}
\hline Criterion & 98 & 7 & 6 & 5 & 4 & 3 & 2 & 1 & 2 & 3 & 4 & 5 & 6 & 7 & 8 & 9 & Criterion \\
\hline Clearance & & & & & & & & & & & & & & & & & $\begin{array}{c}\text { KUF } \\
\text { Toxin removal }\end{array}$ \\
\hline
\end{tabular}

VII- What is the importance of "Ultrafiltration coefficient" in comparison to other criteria?

\begin{tabular}{|c|c|c|c|c|c|c|c|c|c|c|c|c|c|c|c|c|c|c|}
\hline Criterion & 9 & 8 & 7 & 6 & 5 & 4 & 3 & 2 & 1 & 2 & 3 & 4 & 5 & 6 & 7 & 8 & 9 & Criterion \\
\hline KUF & & & & & & & & & & & & & & & & & & Toxin remova \\
\hline
\end{tabular}

VIII- What is the importance of "High-molecular-weight substance removal" in comparison to other criteria?

\begin{tabular}{|c|c|c|c|c|c|c|c|c|c|c|c|c|c|c|c|c|c|c|}
\hline Criterion & 9 & 8 & 7 & 6 & 5 & 4 & 3 & 2 & 1 & 2 & 3 & 4 & 5 & 6 & 7 & 8 & 9 & Criterion \\
\hline High & & & & & & & & & & & & & & & & & & Anaemia \\
\hline Molecule & & & & & & & & & & & & & & & & & & Survival \\
\hline
\end{tabular}


IX- What is the importance of "High-molecular-weight substance removal" in comparison to other criterion?

\begin{tabular}{|c|c|c|c|c|c|c|c|c|c|c|c|c|c|c|c|c|c|c|}
\hline Criterion & 9 & 8 & 7 & 6 & 5 & 4 & 3 & 2 & 1 & 2 & 3 & 4 & 5 & 6 & 7 & 8 & 9 & Criterion \\
\hline Anaemia & & & & & & & & & & & & & & & & & & Survival \\
\hline
\end{tabular}

Please compare among alternatives depending on criterion:

I- Which alternative is more important based on "Cost of dialyser"?

\begin{tabular}{|c|c|c|c|c|c|c|c|c|c|c|c|c|c|c|c|c|c|}
\hline Alternative 9 & 98 & 87 & 6 & 5 & 4 & 3 & 2 & 1 & 2 & 3 & 4 & 5 & 6 & 7 & 8 & 9 & Alternative \\
\hline High Flux & & & & & & & & & & & & & & & & & Low Flux \\
\hline
\end{tabular}

II- Which alternative is more important based on "Membrane material"?

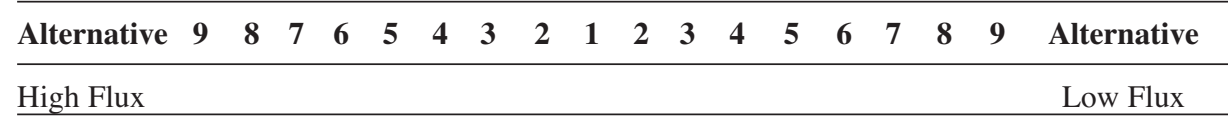

III- Which alternative is more important based on "Medical assessment"?

$\begin{array}{lllllllllllllllllll}\text { Alternative } & 9 & 8 & 7 & 6 & 5 & 4 & 3 & 2 & 1 & 2 & 3 & 4 & 5 & 6 & 7 & 8 & 9 & \text { Alternative }\end{array}$

High Flux Low Flux

IV- Which alternative is more important based on "Technical infrastructure"?

$\begin{array}{lllllllllllllllllll}\text { Alternative } & 9 & 8 & 7 & 6 & 5 & 4 & 3 & 2 & 1 & 2 & 3 & 4 & 5 & 6 & 7 & 8 & 9 & \text { Alternative }\end{array}$

\begin{tabular}{lc}
\hline High Flux & Low Flux \\
\hline
\end{tabular}

V- Which alternative is more important based on "Knowledge"?

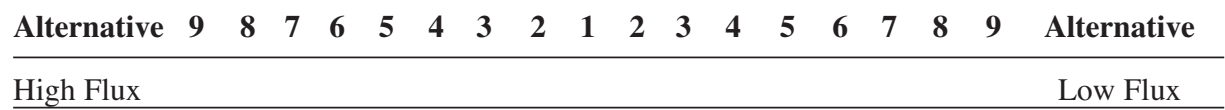

VI- Which alternative is more important based on "Clearance"?

\begin{tabular}{|c|c|c|c|c|c|c|c|c|c|c|c|c|c|c|c|c|c|c|}
\hline Alternative & 9 & 8 & 7 & 6 & 5 & 4 & 3 & 2 & 1 & 2 & 3 & 4 & 5 & 6 & 7 & 8 & 9 & Alternative \\
\hline High Flux & & & & & & & & & & & & & & & & & & Low Flux \\
\hline \multicolumn{19}{|c|}{ VII- Which alternative is more important based on "Ultrafiltration coefficient"? } \\
\hline Alternative & 9 & 8 & 7 & 6 & 5 & 4 & 3 & 2 & 1 & 2 & 3 & 4 & 5 & 6 & 7 & 8 & 9 & Alternative \\
\hline High Flux & & & & & & & & & & & & & & & & & & Low Flux \\
\hline
\end{tabular}


VIII- Which alternative is more important based on "Toxin removal"?

$\begin{array}{lllllllllllllllllll}\text { Alternative } & 9 & 8 & 7 & 6 & 5 & 4 & 3 & 2 & 1 & 2 & 3 & 4 & 5 & 6 & 7 & 8 & 9 & \text { Alternative }\end{array}$

$\underline{\text { High Flux }}$ Low Flux

IX- Which alternative is more important based on "Medical assessment"?

\begin{tabular}{lllllllllllllllllll}
\hline Alternative & 9 & 8 & 7 & 6 & 5 & 4 & 3 & 2 & 1 & 2 & 3 & 4 & 5 & 6 & 7 & 8 & 9 & Alternative
\end{tabular}

High Flux $\quad$ Low Flux

$\mathrm{X}$ - Which alternative is more important based on "High-molecular-weight substance removal"?

\begin{tabular}{lllllllllllllllllll}
\hline Alternative & 9 & $\mathbf{8}$ & $\mathbf{7}$ & $\mathbf{6}$ & $\mathbf{5}$ & $\mathbf{4}$ & $\mathbf{3}$ & $\mathbf{2}$ & $\mathbf{1}$ & $\mathbf{2}$ & $\mathbf{3}$ & $\mathbf{4}$ & $\mathbf{5}$ & $\mathbf{6}$ & $\mathbf{7}$ & $\mathbf{8}$ & $\mathbf{9}$ & Alternative \\
\hline High Flux & 11 & 1 & & & & & & & & & & & & & & & & Low Flux \\
\hline
\end{tabular}

XI- Which alternative is more important based on "Anaemia"?

\begin{tabular}{lllllllllllllllllll}
\hline Alternative & 9 & 8 & 7 & 6 & 5 & 4 & 3 & 2 & 1 & 2 & 3 & 4 & 5 & 6 & 7 & 8 & 9 & Alternative
\end{tabular}

\begin{tabular}{ll} 
High Flux & Low Flux \\
\hline
\end{tabular}

XII- Which alternative is more important based on "Survival"?

\begin{tabular}{lllllllllllllllllll}
\hline Alternative & 9 & 8 & 7 & 6 & 5 & 4 & 3 & 2 & 1 & 2 & 3 & 4 & 5 & 6 & 7 & 8 & 9 & Alternative
\end{tabular}

High Flux $\quad$ Low Flux 


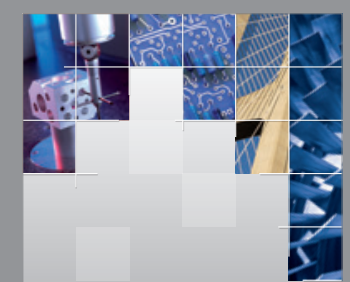

\section{Enfincering}
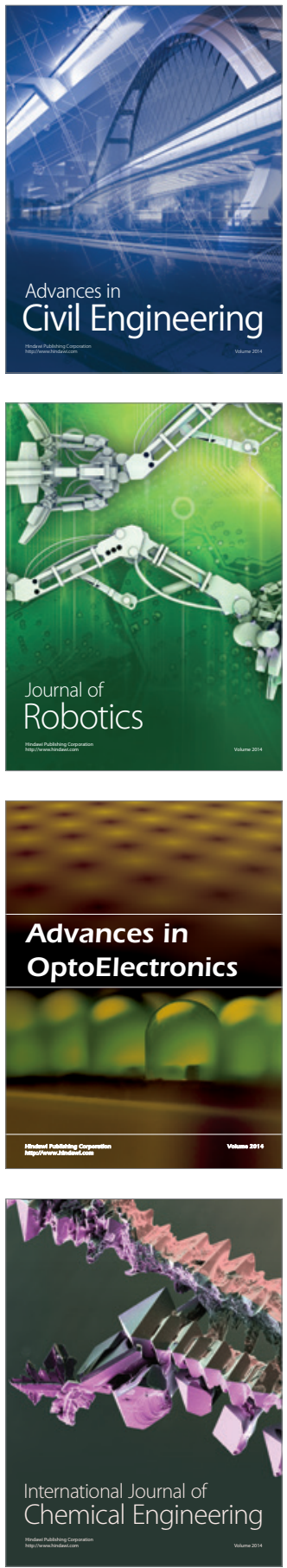

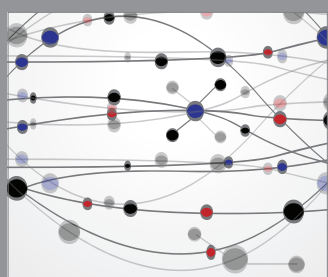

The Scientific World Journal

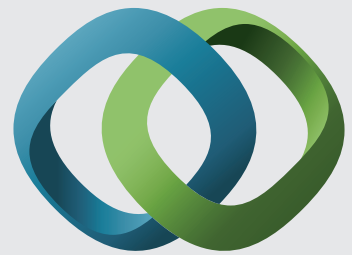

\section{Hindawi}

Submit your manuscripts at

http://www.hindawi.com
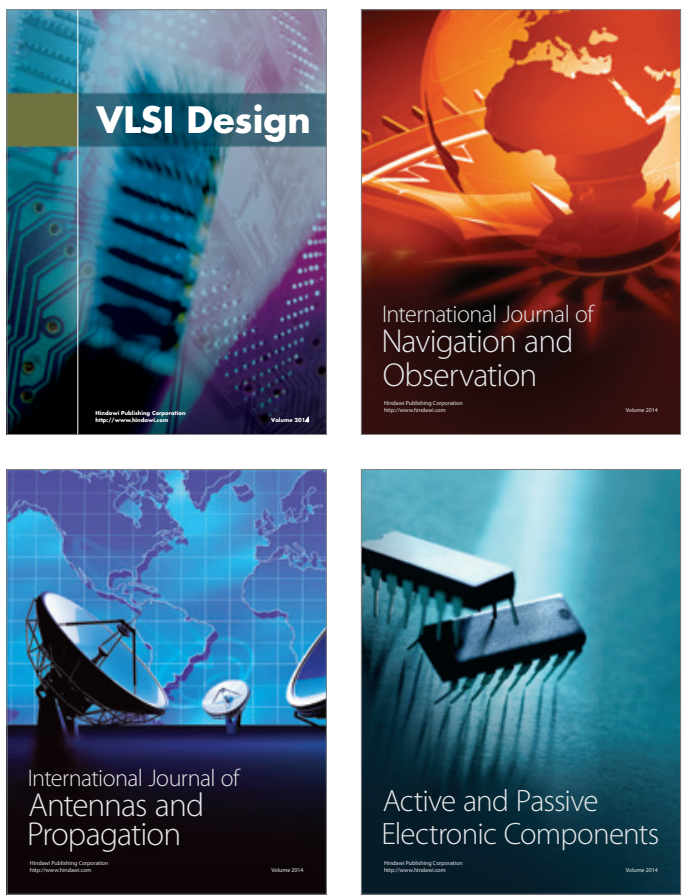
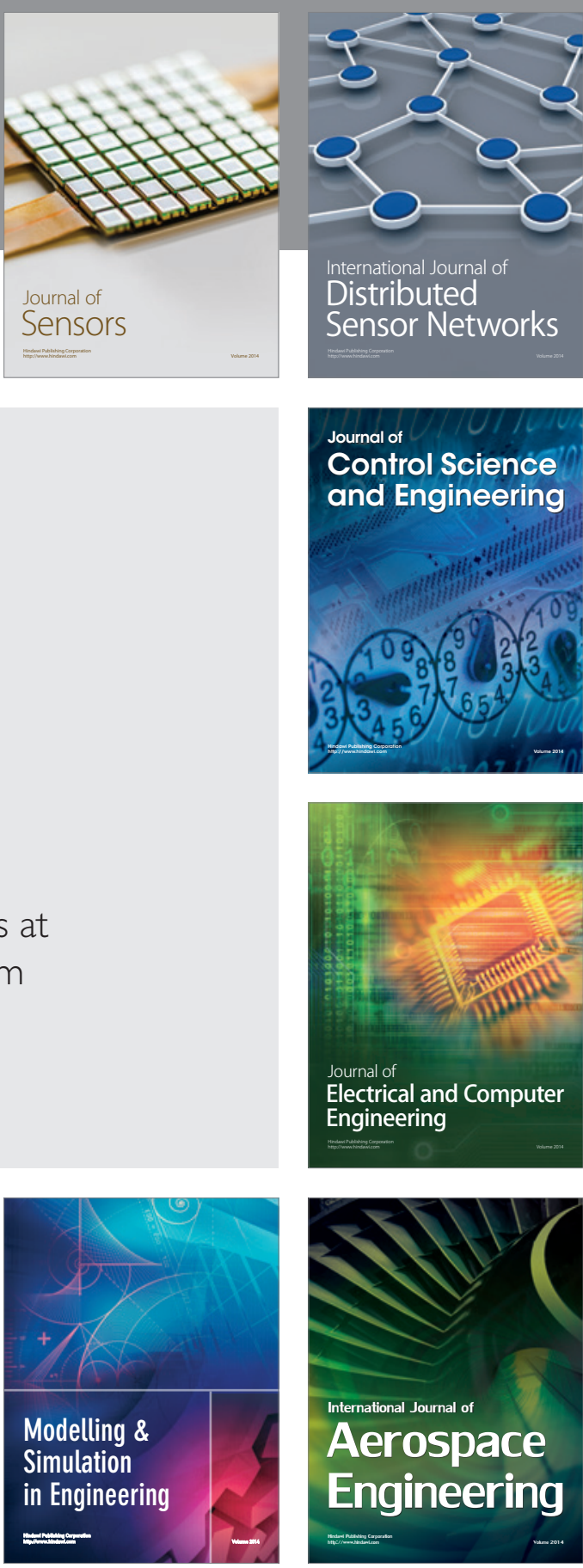

International Journal of

Distributed

Sensor Networks

Journal of

Control Science

and Engineering
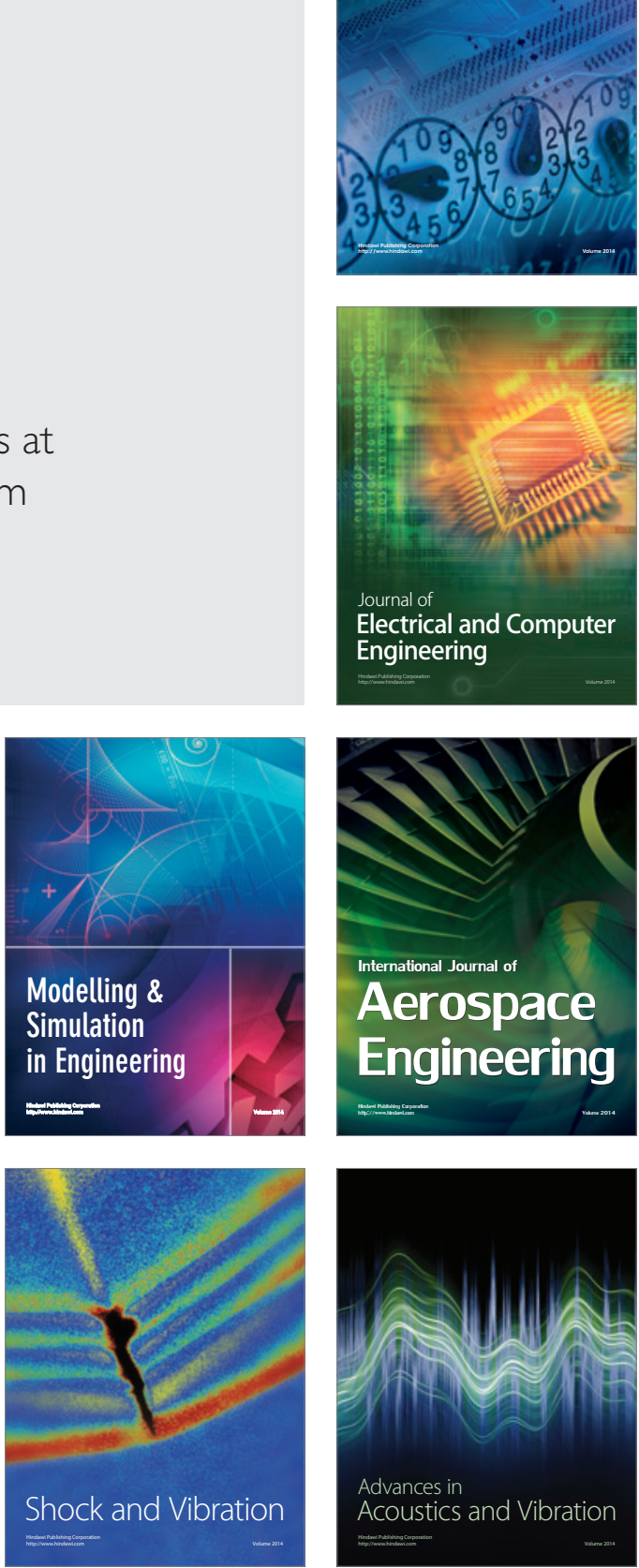